\title{
EL VIDEOJUEGO COMO TEXTO: UNA EXPERIENCIA DE EXPLORACIÓN DE MUNDOS NARRATIVOS
}

\author{
Dan TARODO CORTES \\ Universidad de Zaragoza \\ dtc.unizar@gmail.com
}

\section{1}

\section{La dimensión textual del videojuego}

Los videojuegos se han convertido en los últimos años en una nueva área de estudio dentro del ámbito de la comunicación. Este nuevo e ilusionante campo académico, denominado internacionalmente Game Studies, entró tímidamente en las aulas y los departamentos de las universidades, de una manera similar a como lo hicieron los estudios sobre el cine y otros medios audiovisuales en las primeras décadas del pasado siglo XX.

El teórico de la comunicación audiovisual y del videojuego Martínez Fabre destaca, en esta línea, que «al videojuego (entendiéndolo como un texto que se expresa mediante su propio lenguaje) se le puede describir como una organización de signos interrelacionados cuyo principal fin es la plasmación de un discurso» (2013: 10). Un discurso que crea una experiencia narrativa mediante el entrelazamiento de distintos lenguajes: escrito (en las cajas de diálogo y menús), audiovisual (imágenes, voces y música) y lúdico (reglas de juego e interactividad).

La importancia de esta consideración del videojuego como ente narrativo podemos sostenerla con las palabras del analista textual Jesús González Requena, que retoma la inveterada tradición del hombre como animal narrativo:

Todo ser humano se construye narrativamente. Su identidad es narrativa, su localización en el mundo es a través de los relatos, su manera de enfrentar las pesadillas es con relatos. En el individuo, todo está organizado por relatos (en Gobantes, 2014: 39).

De esta forma, vamos a acercarnos al concepto de narración, rescatando las ideas fundamentales de los más importantes teóricos literarios para después centrarnos en la concepción de mundo narrativo y su aplicación al videojuego. «El poder de las palabras es determinante para construir los espacios humanos. Los textos construyen los espacios y los sujetos» (González Requena, en Gobantes, 2014: 44). 


\section{De la mímesis al concepto de mundo posible}

Para abordar cualquier aspecto relacionado con la narrativa -incluso en un medio tan novedoso como el videojuego-, debemos remontarnos al tratado de teoría literaria más antiguo de la cultura occidental: la Poética de Aristóteles. Cabe destacar que las dos obras aristotélicas que han perdurado a través del paso de los milenios y han llegado a nosotros con mayor reconocimiento, la Poética y la Retórica, tienen por objeto de estudio la comunicación como actividad humana básica (Murphy, 2011: 220).

El tratado aristotélico presenta la poderosa idea de «mímesis», es decir, que los textos literarios imitan la realidad, la construyen a su imagen y semejanza. El filósofo griego justifica esta interpretación por considerar la imitación un rasgo propio de la naturaleza humana:

El hecho de imitar es, en efecto, algo connatural al hombre desde la infancia y en esto se diferencia de los demás animales, en que es sumamente apto para la imitación y adquiere sus primeros conocimientos imitando; y también le es connatural el hecho de que todos se complacen en las imitaciones (Poética, IV: $1448 b)$

Distingue así los dos tipos principales de creaciones miméticas, división de la poesía narrativa clásica: el «drama» (trágico y cómico) y la «épica». Sin embargo, Aristóteles no otorga la misma atención a uno y a otra, pues dedica diecinueve de los veintiseis capítulos conservados de la Poética al drama y tan solo cuatro a la épica. El erudito en filología clásica James J. Murphy justifica esta focalización en la poesía dramática argumentando que «a pesar de que en ningún momento de la Poética se afirma de un modo explícito, Aristóteles cree firmemente que el drama es una creación comunicativa» (2011: 211). Esta dimensión comunicativa del drama griego es doble: deleitar e instruir al público, ligada a conceptos morales (Murphy, 2011:211).

La genialidad aristotélica va más allá de la mera delimitación de la estructura dramática — tripartita en «principio, medio y fin» (Poética, VIII: 1450b) - e identifica sus elementos causativos: argumento, personaje, pensamiento, dicción, espectáculo y melodía (Murphy, 2011: 210-211). El orden de los mismos plasma una cadena causal en la que el argumento -elección moral que solo depende del autor - tiene el mayor peso que el resto y determina los demás elementos: «el argumento es el fin de la tragedia y el fin es lo más importante de todo» (Poética, VI: 1450a). A partir de él se determina «quién será el personaje; el personaje determina el pensamiento que expresará en escena; el pensamiento determina su dicción o lenguaje; y el espectáculo y melodía deben estar en consonancia con estos cuatro elementos» (Murphy, 2011: 211).

Este brevísimo recorrido por los hitos de las teorías sobre la narración nos obliga a saltar veinticuatro siglos después de Aristóteles, en concreto a 1928, cuando el estudioso del folclore Vladimir Propp revolucionó la concepción del análisis de relatos con su Morfología del cuento, texto del que beben prácticamente todas las aportaciones de autores posteriores.

La revolución teórica de Propp radica en proponer una unidad narrativa mínima para analizar los cuentos llamada «función». Mientras que los personajes y sus atributos varían de unas historias a otras, sus acciones permanecen constantes, de manera que los personajes forman parte de una suerte de 
«envoltorio variable» del cuento, mientras que las funciones forman parte de su esencia y son atribuidas a multitud de personajes en cuentos distintos.

Propp entiende la función como «la acción de un personaje, definida desde el punto de vista de su significado en el desarrollo de la intriga» (1928: 32). En este sentido, para el teórico ruso estas funciones son constantes, lo que «nos permite estudiar los cuentos a partir de las funciones de los personajes» (Propp, 1928: 30). Otra de sus características es su número limitado - restringe su cantidad a treinta y una- donde ninguna función sustituye a otra, ya que todas pertenecen a un mismo eje (Propp, 1928: 84).

Esta lista representa la base morfológica de los cuentos maravillosos en general (Propp, 1928: 37-38) e integra funciones como la partida, la prueba, el viaje, la lucha, la persecución, la tarea difícil, el reconocimiento o la boda y ascenso al trono, entre otras. Todas estas acciones son fácilmente reconocibles no solo en los cuentos maravillosos, sino en una gran mayoría de los argumentos de los videojuegos de aventuras o rol. Este tipo de juegos hereda directamente algunos elementos de la narrativa tradicional y esto permite que puedan ser interpretados como una suerte de cuentos interactivos.

Aunque el concepto de personaje queda en segundo plano en la teoría de Propp, el autor se hace la pregunta de cómo se reparten las funciones los personajes. Surge así el interesante concepto de las «esferas de acción», que corresponden a los personajes que llevan a cabo sus respectivas funciones. De esta forma, Propp distingue siete esferas de acción: la del agresor, la del donante, la del auxiliar, la de la princesa (y su padre), la del mandatario, la del héroe y la del falso héroe (Propp, 1928: 105-106).

La tesis sobre la narrativa de Paul Ricœur parte de la idea de mímesis aristotélica, aunque aporta un nuevo e interesante matiz a la concepción original de mera imitación. Para el filósofo y antropólogo francés, la ficción narrativa «imita» la acción humana en la medida en que contribuye a remodelar la realidad según la configuración imaginaria de la historia. De esta manera, el «mundo del texto interviene en el mundo de la acción para configurarlo o, me atrevería a decir, para transfigurarlo» (Ricœur, 2000: 199).

En esta configuración juega un papel crucial la temporalidad: cualidad que se torna en una auténtica unidad funcional común a todos los géneros narrativos. Dicho en otras palabras, «todo lo que se cuenta sucede en el tiempo, arraiga en el mismo, se desarrolla temporalmente; y lo que se desarrolla en el tiempo puede narrarse» (Ricœur, 2000: 190).

Tras este telón de temporalidad se estructura el potente concepto de «trama». Para Ricœur «la trama es el conjunto de combinaciones mediante las cuales los acontecimientos se transforman en una historia o - correlativamente- una historia se extrae de acontecimientos. La trama es la mediadora entre el acontecimiento y la historia» (2000: 192). Haciendo alusión a la idea de configuración de la realidad que poseen todos los sistemas simbólicos propuesta por el filósofo francés, podemos subrayar que «las tramas nos ayudan a configurar nuestra experiencia temporal confusa, informe y, en última instancia, muda» (Ricœur, 2000: 190). 
Una característica clave de la trama es que sintetiza y se compone de factores tan heterogéneos como las circunstancias, los personajes con sus proyectos y motivos, las interacciones de cooperación, hostilidad, ayuda e impedimento o incluso la casualidad (Ricœur, 2000: 197). Esta integración de lo heterogéneo convierten a la trama en un poderoso instrumento desde el que podemos explicar las narraciones.

Por su parte, el narratólogo Jean-Michel Adam coincide con Ricœur en que el relato parte de la sucesión temporal de acciones, pero Adam une a esta circunstancia la obligación a que se realice o fracase una transformación de las propiedades iniciales de los personajes mediante una puesta en intriga que estructure y dé sentido a la sucesión de acciones y acontecimientos en el tiempo (2005: 499).

Conviene rescatar en este momento la distinción de Gérard Genette entre acto de contar, historia contada y puesta en texto (en Adam, 2005: 499). No nos detendremos en el acto de narrar, ni en la textualización por alejarse de la manera en la que se dan en el videojuego, respecto otros soportes narrativos. Sin embargo, la «historia contada» o diégesis sí que es un concepto que puede arrojar luz en este campo y nos acerca a la idea de mundo narrativo. Para Adam, la diégesis alude precisamente al mundo que construye cada relato: el espacio y el tiempo; los acontecimientos; y los actos, las palabras y los pensamientos de los personajes (Adam, 2005: 500). Este universo diégetico es construido interpretativamente por el lector sobre lo mostrado por el texto, objeto que se comporta como una «máquina perezosa», según Umberto Eco, que requiere de la «cooperación interpretativa» del lector para llenar los vacíos, blancos y elipsis de esta historia contada (en Adam, 2005: 501).

A partir de esta aproximación al concepto de mundo narrativo llegamos a la teoría de los mundos posibles de Lubomír Doležel. En la década de los noventa, el teórico checo marcó un antes y un después en los estudios narratológicos al alejarse de la idea de mímesis aristotélica para proponer un nuevo paradigma para explicar la ficción narrativa.

Doležel no destruye la teoría de la mímesis sino que la reconstruye, pasando de una idea de mímesis tradicional —en la que los particulares ficcionales representan particulares reales (1997: 71) - a una idea de «pseudomímesis», donde es la fuente real la que representa — proporciona la representación - al particular ficcional (1997: 75).

Mediante este giro interpretativo se superan las dificultades de la teoría mimética que surgen al vincular las ficciones exclusivamente al mundo real (Doležel, 1997: 77). Desde la premisa de que «nuestro mundo real está rodeado por una infinidad de otros mundos posibles» (Bradley y Swartz, en Doležel, 1997: 78), el teórico checo articula su «semántica de los mundos posibles» basada en tres tesis fundamentales (Doležel, 1997: 79-83):

1. Los mundos ficticios son conjuntos de estados de cosas posibles. Se trata, en todo caso, de un conjunto de particulares ficcionales con homogeneidad ontológica, es decir, con el mismo grado de «realidad» dentro de su estatus de posibles no realizados. Se puede postular relación entre estos particulares y sus fuentes reales 
-por ejemplo, el Napoleón histórico y todos los Napoleones ficcionales - aunque solo como una identificación inter-mundos protegida por la frontera entre los mundos real y posibles.

\section{El conjunto de mundos ficcionales es ilimitado y variado al máximo. Esto es así} ya que las posibilidades alternativas a lo real son infinitas y todas ellas están sustentadas bajo una misma semántica, es decir, los relatos realistas son tan ficcionales como los cuentos de hadas o ciencia ficción. El teórico checo añade además que «podemos generar no solo los consabidos mundo natural y sobrenatural, sino el mundo híbrido, que ha pasado desapercibido hasta ahora» (Doležel, 1997: 80-81).

3. Los mundos ficcionales son accesibles desde el mundo real. Este acceso no es posible de forma física, sino a través de canales semióticos (libros, cine, televisión, videojuegos...). Gracias a esta mediación los mundos ficcionales pueden ser fuente de experiencia para los lectores reales, de una forma similar a la observación del mundo real mediante la experiencia.

Regidos por estas tres principios, los mundos ficcionales a su vez pueden caracterizarse por tres rasgos distintivos. El primero de ellos es que son incompletos (Doležel, 1997: 84), es decir, solo podemos conocer de su ontología aquellos datos que nos proporciona el canal semiótico. En el caso del mundo realista es más o menos sencillo rellenar esas lagunas, pero en casos de mundo fantástico o híbrido esta no compleción puede ser utilizada como fin estético, para crear intriga o provocar la elucubración del receptor del texto en cuestión.

El segundo de los rasgos característicos de los mundos ficcionales es que muchos de ellos no son semánticamente homogéneos (Doležel, 1997: 86). Un ejemplo de esto es cualquier tipo de mundo híbrido, como el mundo mitológico, que se constituye por la coexistencia de los dominios naturales y sobrenaturales - por ejemplo, el tipo de mundo en el que se ambienta la saga de videojuegos Pokémon- (Game Freak, 1996-2016).

Por último, el tercero de los rasgos propios de los mundos ficcionales es que siempre son constructos de la actividad textual (Dolezel, 1997: 87). En oposición a la propuesta de Leibniz de que «los mundos posibles adquieren su existencia ficcional al ser descubiertos» (en Doležel, 1997: 88), la tesis de Lubomír Doležel sentencia que «los mundos posibles no se descubren [...] sino que son construidos por mentes y manos humanas» (1997: 88).

Esta poderosa concepción del mundo ficcional resulta de gran utilidad en la tarea de describir la narrativa de los videojuegos y se han servido de ella numerosos teóricos de la materia. En la mayoría de los videojuegos, más que trazarse el hilo narrativo de una historia, se transita por vastos mundos en los que se crean historias, gracias a su factor interactivo y, en mayor o menor medida, la libertad de movimientos. Nos acercamos en el siguiente epígrafe a las teorías más sólidas que nos ofrecen el videojuego como un mundo narrativo. 


\section{El videojuego como mundo diegético: una experiencia de exploración narrativa}

Después de este repaso breve pero que recoge las nociones clave que se han dado sobre la narración a lo largo de la historia de la teoría literaria, volvemos en este punto a una de las autoras con las nacieron los Game Studies: Janet Murray. La narratóloga americana apuesta por la idea de que la narrativa digital no es lineal sino algo que denomina narrativa multiforme que evoca la tenebrosa historia de Jorge Luis Borges «El jardín de senderos que se bifurcan» (Murray, 1999: 42). La concepción del tiempo en el cuento de Borges plantea un tiempo que «no es una línea "absoluta y uniforme" sino una "red" infinita que incluye cualquier posibilidad» (Murray, 1999: 43).

Para Murray, este caudal de posibilidades que nos ofrece la metáfora del mundo del videojuego como un laberinto debe encontrar su equilibrio en «historias lo suficientemente motivadas como para orientarnos en la navegación, pero lo suficientemente abiertas como lo suficientemente abiertas como para que la exploración sea libre» (1999: 147).

Esta noción de «libertad dirigida» — profundamente estudiada por Víctor Navarro (2016) — nos lleva a preguntarnos sobre quién recae el papel de «autor» $\mathrm{o}$ «narrador» en el texto digital. Para Murray el diseñador del juego crea un mundo de posibilidades narrativas entre las que el usuario o jugador puede elegir en una acción que no se puede denominar autoría sino «actuación» (1999: 165-166).

En esta línea teórica, el comunicólogo Henry Jenkins propone que los diseñadores de videojuegos han de ser tratados como «arquitectos narrativos» y no como meros «narradores» ya que son los encargados de confeccionar escenarios cargados de connotaciones culturales y referencias simbólicas para que sea el usuario quien construya sus propias historias al interactuar con ellos (en Ramírez, 2012: 11), idea heredera de la de «actuación» en la teoría narrativa de Murray.

Surge así el concepto de «historia espacial», es decir, aquellas historias que se caracterizan por una construcción enciclopédica de mundos posibles más que por la profundidad psicológica de los personajes o el desarrollo de una trama (Jenkins, en Ramírez, 2012: 12). Este concepto de «mundo espacial» se convierte en el núcleo de la concepción «mundo transmedia», acuñada por el mismo Jenkins. Se trata de productos culturales en los que existe un mundo narrativo al que se puede acceder mediante diferentes canales semióticos «que se expresan a través de una combinación de lenguajes, medios y plataformas» (Scolari, 2013: 25). En la actualidad, la narrativa transmedia es una de las líneas de investigación que más está siendo en explotada por investigadoras de prestigio como Marie-Laure Ryan, Lisbeth Klastrup o la española Susana Pajares Tosca (Scolari, 2013: 26).

En 2012 apareció una obra de referencia en el panorama español de los Game Studies, de la mano de Óliver Pérez Latorre: El lenguaje videolúdico: análisis de la significación del videojuego. Siguiendo la estela de las teorías explicadas en el punto anterior, la obra propone un modelo de análisis del videojuego donde se conjugan elementos de las nuevas teorías de diseño de juegos con otras teorías clásicas de las Ciencias de la Comunicación y las Humanidades (2012: 35).

Este modelo analítico global consta de tres dimensiones: la dimensión lúdica —el videojuego como juego o conjunto de reglas—; la dimensión narrativa —el videojuego como narración-; y la dimensión enunciativa —el videojuego como diálogo entre el diseñador implícito y el jugador 
implícito- (Pérez Latorre, 2012: 36). Dado que estas tres dimensiones de análisis de significación pueden aplicarse de forma integrada o de manera individual, para el desarrollo del presente trabajo nos quedaremos solo con la dimensión narrativa del mismo.

Dentro de las diferentes posibilidades de análisis narrativo que ofrece Pérez Latorre, el autor da especial importancia a una de ellas: la que considera el videojuego un mundo narrativo - concepto emparentado con la idea de narrativa espacial que proponía Jenkins-. Esta concepción cósmica del juego electrónico está justificada porque «la narrativa del videojuego consiste, ante todo en la construcción de mundos narrativos, más que en el relato de historias» (Pérez Latorre, 2012: 214). Mundos complejos donde los jugadores crean historias a partir de un abanico de narraciones posibles.

Desde este estudio, los fundamentos estructurales de estos mundos diegéticos parten de la teoría de los mundos ficcionales de Lubomír Dolezel — que abordamos en el epígrafe anterior del presente artículo- y se basan en una idea clave:

Mientras la narración/trama tiende a desarrollarse en clave de cadena de acontecimientos, a través de una linealidad temporal apuntada hacia delante, un mundo narrativo tiende a desarrollarse, fundamentalmente, a través de la expansión progresiva del mundo representado y la profundización sobre la información relativa a dicho mundo (Pérez Latorre, 2012: 215).

Partiendo de esta idea, el teórico advierte de que hasta el momento no existe un modelo de análisis textual preciso y concebido en clave transversal para textos tanto interactivos como no interactivos (Pérez Latorre, 2012: 215). Por ello, propone un modelo para identificar estructuralmente estos mundos basado en siete marcas de cosmicidad $^{1}$ narrativa (2012: 218-225):

1. Estructuras de red versus Cadena de acontecimientos: la primera opción es más propia de una interpretación en clave de mundo narrativo, mientras que la segunda caracteriza a una noción convencional de narración lineal.

2. Subversiones de la progresión temporal: las rupturas de la linealidad cronológica (analepsis, prolepsis, elipsis...) aumentan la cosmicidad de la obra videolúdica.

3. Expansividad / profundización en el mundo narrativo: casos de narrativa «expansiva» (como el desbloqueo de nuevas zonas o el relato de un mismo evento desde puntos de vista diferentes) aumentan la interpretación del videojuego como mundo diegético.

4. Un entorno claramente delimitado: un entorno «cerrado» que aísla a sus individuos del exterior otorga un plus de proyección como mundo narrativo.

5. Riqueza informativa del texto sobre el entorno natural y cultural: una descripción exhaustiva del entorno natural, social y cultural favorece la interpretación cósmica de un texto.

\footnotetext{
${ }^{1}$ Este término es una traducción literal realizada por Óliver Pérez del original worldness, contenido en la teoría de Lisbeth Klastrup y Susana P. Tosca. Es una magnitud gradual, ya que «no todo videojuego u obra ficcional, aunque posea carácter plurinarrativo, resulta igual de susceptible de ser interpretado como mundo narrativo (Pérez Latorre, 2012: 219).
} 
El videojuego como texto: una experiencia de exploración de mundos narrativos

6. Códigos culturales o de interacción internos: las reglas de juego son connaturales a los videojuegos, una mayor singularidad en las mismas eleva el valor cualitativo de la cosmicidad del juego.

7. Expectativas sobre la trama versus Actividad imaginada: en la narración lineal los usuarios construyen especulaciones en torno a la trama - sucesión de acciones-, mientras que en una narración construida como mundo las aportaciones imaginadas van más allá, potenciando una creatividad que lleva a reflexionar sobre el propio mundo o crear alternativas al mismo.

En conclusión, la aplicación de este modelo teórico nos servirá para identificar la proyección del texto en un mundo diegético. La suma de varias de estas marcas de cosmicidad en el análisis de un texto videolúdico alentarían su interpretación en clave de mundo narrativo (Pérez Latorre, 2012: 225).

En esta línea de investigación es notable la aportación posterior de Antonio José Planells (2015) en cuyo trabajo caracteriza los mundos de los videojuegos como «mundos ludoficcionales», ampliando la concepción del juego un paso más allá del mundo narrativo. El teórico afirma que «el mundo ludoficcional representa un gran marco de ficción que contiene distintos mundos» (2015: 97), es decir, un espacio en el que el jugador, mediante su interactuación con el personaje-avatar puede hacer emerger diferentes mundos posibles (uno en el personaje vence, otro en el que falla y cae derrotado ante el villano, etc.).

\section{Bibliografía}

ADAM, J.-M. (2005): «Relato», en P. CHARAUdEAU y D. MAINGUENEAU, dirs., Diccionario de análisis del discurso. Buenos Aires, Amorrortu.

ARISTÓteles (2011): Poética. Madrid, Itsmo / Akal.

DoleŽEl, L. (1997): «Mímesis y mundos posibles», en A. GARRIDO DomínguEZ, comp., Teorías de la ficción literaria. Madrid, Arco, pp. 69-94.

Gobantes Bilbao, M. (2014): El texto y el abismo. Diálogos con González Requena. Madrid, Sans Soleil.

JENKINS, H. (2004): «Game design as narrative architecture», en N. WARDRIP-FRUIN y P. HARRRIGAN, eds., First Person: New Media as Story, Performance and Game. Cambridge, The MIT Press, en http://interactive.usc.edu/blog-old/wp-content/uploads/2011/01/Jenkins_Narrative_Architecture .pdf (última consulta, 1-4-2016).

MARTínez FABre, M.-P. (2013): «Game Play abierta. Intertextualidad, intermedialidad y autorreferencia en la partida de juego», Life Play, 1, pp. 9-26, en http://www.lifeplay.es/ volumen1/Dossier /009_026_MARTINEZ\%20FABRE.pdf (última consulta, 1-4-2016).

Murphy, J. J. (2011): «Epílogo: La poética de Aristóteles», en Aristóteles (2011). 
Murray, J. H. (1999): Hamlet en la holocubierta: El futuro de la narrativa en el ciberespacio. Barcelona, Paidós.

NAVARro Remesal, V. (2016): Libertad dirigida: Una gramática del análisis y diseño de los videojuegos. Santander, Shangrila Textos Aparte.

PÉREZ LATORRe, Ó. (2012): El lenguaje videolúdico: análisis de la significación del videojuego. Barcelona, Leartes.

Planells de la MaZA, A. J. (2015): Videojuegos y mundos de ficción. De Super Mario a Portal. Madrid, Cátedra.

Propp, V. (1928): Morfología del cuento. Madrid, Akal, 6a reimp., 2014.

RAMíREZ MORENO, C. (2012): Del avatar a la persona: Introducción al análisis del personaje en el videojuego. Sevilla, Universidad de Sevilla, en https://www.academia.edu/3104385/ Del_avatar_a_la_persona_Introduccion_al_analisis_del_personaje_en_el_videojuego_TFM (última consulta, 1-4-2016).

RICEUR, P. (2000): «Narratividad, fenomenología y hermenéutica», Anàlisi: quaderns de comunicació i cultura, 25, pp. 189-207.

SCOLARI, C. A. (2013): «Read me first. Entre la narrativa y la interacción: el videojuego como objeto de estudio científico» en Carlos A. Scolari, ed., Homo Videoludens 2.0. De Pacman a la gamification. Barcelona, Laboratorio de Medios de la Universidad de Barcelona, en http://hipermediaciones.com/2013/12/08/homo-videoludens-2-0-en-version-libre-y-gratuita/ (última consulta, 1-4-2016). 